\title{
Clinical Stage I Merkel Cell Carcinoma AJCC v8
}

National Cancer Institute

\section{Source}

National Cancer Institute. Clinical Stage I Merkel Cell Carcinoma A/CC v8. NCI Thesaurus.

Code C136873.

Stage I includes: T1, N0, M0. T1: Maximum clinical tumor diameter equal to or less than 2 cm. N0: No regional lymph node metastasis detected on clinical and/or radiologic examination. M0: No distant metastasis detected on clinical and/or radiologic examination. (AJCC 8th ed.) 